Article

\title{
Association between Skeletal Muscle Loss and the Response to Neoadjuvant Chemotherapy for Breast Cancer
}

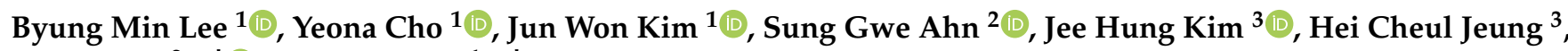 \\ Joon Jeong $2, *,+(\mathbb{D})$ and Ik Jae Lee ${ }^{1, *,+}$ \\ 1 Department of Radiation Oncology, Yonsei University College of Medicine, Seoul 03722, Korea; \\ bmlee9125@yuhs.ac (B.M.L.); iamyona@yuhs.ac (Y.C.); junwon@yuhs.ac (J.W.K.) \\ 2 Department of Surgery, Yonsei University College of Medicine, Seoul 03722, Korea; asg2004@yuhs.ac \\ 3 Division of Medical Oncology, Yonsei University College of Medicine, Seoul 03722, Korea; \\ ok8504@yuhs.ac (J.H.K.); jeunghc1123@yuhs.ac (H.C.J.) \\ * Correspondence: gsjjoon@yuhs.ac (J.J.); ikjae412@yuhs.ac (I.J.L.); Tel.: +82-(22)-019-3379 (J.J.); \\ +82-(22)-019-3152 (I.J.L.) \\ + These authors have contributed equally to this work.
}

check for

updates

Citation: Lee, B.M.; Cho, Y.; Kim, J.W.; Ahn, S.G.; Kim, J.H.; Jeung, H.C.; Jeong, J.; Lee, I.J. Association between Skeletal Muscle Loss and the Response to Neoadjuvant Chemotherapy for Breast Cancer. Cancers 2021, 13, 1806. https:// doi.org/10.3390/cancers13081806

Academic Editor: David Wong

Received: 22 February 2021

Accepted: 6 April 2021

Published: 9 April 2021

Publisher's Note: MDPI stays neutral with regard to jurisdictional claims in published maps and institutional affiliations.

Copyright: (c) 2021 by the authors. Licensee MDPI, Basel, Switzerland. This article is an open access article distributed under the terms and conditions of the Creative Commons Attribution (CC BY) license (https:// creativecommons.org/licenses/by/ $4.0 /)$.
Simple Summary: The loss of skeletal muscle mass is known to be associated with poor treatment outcome, treatment-related toxicity, and high mortality. The association between loss of skeletal muscle mass and the response to treatment is not well-defined yet. In this study, we evaluated the impact of loss of skeletal muscle mass on responsiveness to neoadjuvant chemotherapy in breast cancer. The prediction of response to neoadjuvant chemotherapy could be helpful to guide the treatment direction.

Abstract: There are no means to predict patient response to neoadjuvant chemotherapy (NAC); the impact of skeletal muscle loss on the response to NAC remains undefined. We investigated the association between response to chemotherapy and skeletal muscle loss in breast cancer patients. Patients diagnosed with invasive breast cancer who were treated with NAC, surgery, and radiotherapy were analyzed. We quantified skeletal muscle loss using pre-NAC and post-NAC computed tomography scans. The response to treatment was determined using the Response Evaluation Criteria in Solid Tumors. We included 246 patients in this study (median follow-up, 28.85 months). The median age was 48 years old (interquartile range $42-54)$ and 115 patients were less than 48 years old (46.7\%). Patients showing a complete or partial response were categorized into the responder group (208 patients); the rest were categorized into the non-responder group (38 patients). The skeletal muscle mass cut-off value was determined using a receiver operating characteristic curve; it showed areas under the curve of 0.732 and 0.885 for the pre-NAC and post-NAC skeletal muscle index $(p<0.001$ for both), respectively. Skeletal muscle loss and cancer stage were significantly associated with poor response to NAC in locally advanced breast cancer patients. Accurately measuring muscle loss to guide treatment and delaying muscle loss through various interventions would help enhance the response to NAC and improve clinical outcomes.

Keywords: breast cancer; skeletal muscle loss; treatment-induced cachexia

\section{Introduction}

Neoadjuvant chemotherapy (NAC) for breast cancer has a high clinical response rate. In some cases, NAC facilitates the conversion of unresectable, locally advanced breast cancer to operable cancer $[1,2]$. Consequently, conversion to resectable status leads to an increase in the breast conservation rate $[3,4]$. Some patients undergoing NAC for breast cancer show an insufficient response to therapy. Currently, we do not have the means to predict whether patients will respond well to NAC or not. 
The loss of skeletal muscle mass is known to be a poor prognostic factor in patients with malignancies. It is highly associated with chemotherapy toxicity [5,6], tumor progression [6], and mortality [7]. The impact of skeletal muscle loss on the response to treatment remains undefined. Although there is no established standard method for skeletal muscle quantification, computed tomography (CT) is used to measure the skeletal muscle mass. CT images are frequently obtained for cancer patients as a part of staging and evaluating the progress of disease during treatment.

To our knowledge, this study is the first to investigate the association between skeletal muscle loss and responsiveness to NAC. In this study, we analyzed the association between skeletal muscle loss and the response to NAC to evaluate the impact of skeletal muscle loss in patients receiving NAC for locally advanced breast cancer. Being able to predict the response to NAC would help guide the treatment direction.

\section{Patients and Methods}

\subsection{Patient Population}

Patients diagnosed with breast cancer who were treated with NAC, surgery, and radiotherapy (RT) from March 2013 to September 2019 were included and analyzed. The chemotherapy regimen and schedule were decided at the physician's discretion. The clinical and laboratory data of patients were collected through electronic medical records.

We analyzed 246 patients in total. The inclusion criteria for the patients were as follows: (1) age more than 18 years, (2) treatment with either partial mastectomy or total mastectomy, (3) treatment with NAC and adjuvant RT, and (4) available medical records. The exclusion criteria for patients were as follows: (1) follow-up loss, (2) inability to measure the skeletal muscle mass, and (3) synchronous malignancies. Every patient in this study received neoadjuvant chemotherapy, operation, and adjuvant radiotherapy. The adjuvant radiotherapy was performed in patients with tumor stage III/IV or extensively positive lymph node initially among the patients who underwent total mastectomy. This study was approved by the institutional review board of Gangnam Severance Hospital (3-2020-0509). Because the study was retrospective, the need for written informed consent was waived.

\subsection{Measurement of Body Composition and the Definition of Skeletal Muscle Loss}

$\mathrm{CT}$ was used to measure body composition. Generally, skeletal muscle mass is evaluated at the level of the third lumbar vertebra (L3) on abdominal/pelvic CT scans. Most of the patients in our study underwent abdominal/pelvic CT for the assessment of metastatic lesions. However, a few patients did not undergo abdominal/pelvic CT. Some recent studies have evaluated the skeletal muscle index (SMI) at the level of the fourth thoracic vertebra (T4) on chest CT scans [8,9]. Similarly, we assessed the SMI at the upper border of T4 (Figure 1).

We estimated the SMI using CT scans taken within 3 months of diagnosis and those taken for radiotherapy (RT) simulations. CT was performed before the initiation of NAC and after the completion of NAC; thus, pre-NAC and post-NAC CT scans were obtained for each patient. We used the MIM Vista software (MIM corp., Version 6.6.14., Cleveland, OH, USA) to delineate the body composition based on Hounsfield units (HUs). The following HU threshold was applied for skeletal muscle delineation: from -29 to +150 . The crosssectional volumes obtained from the MIM software at the T4 level were divided by the thickness of the axial slice and defined as the cross-sectional areas. The SMI was calculated by dividing the cross-sectional areas by the height of the patients.

Similar to skeletal muscle, subcutaneous adipose tissue composition was delineated based on HUs: -190 to $-30 \mathrm{HU}$. The subcutaneous adipose tissue index was determined by dividing the cross sectional volume of subcutaneous adipose tissue at the T4 level with thickness of axial slice. 


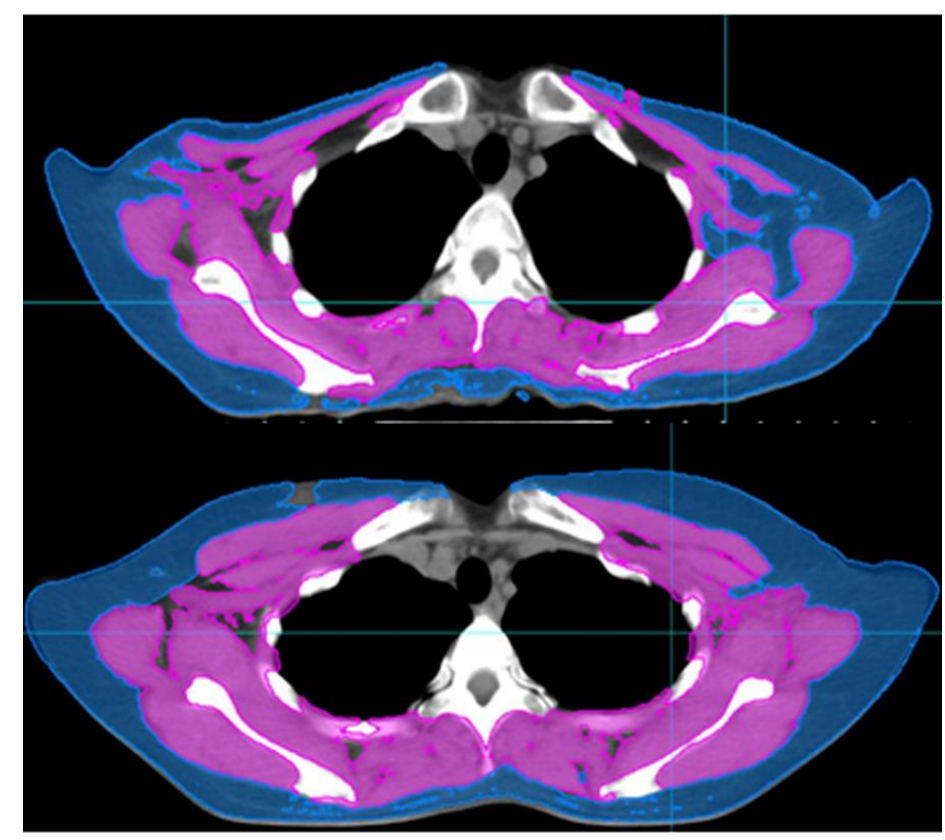

Figure 1. Computed tomography images of patients with skeletal muscle loss (upper) and without skeletal muscle loss (lower). skeletal muscle index of upper image: 4.88, skeletal muscle index of lower image: 9.83 .

\subsection{Statistical Analysis}

We aimed to investigate the association between skeletal muscle loss status and responsiveness to treatment. Responsiveness to treatment was evaluated according to the Response Evaluation Criteria in Solid Tumors [10]. The treatment response was evaluated based on the image study of the patients. Magnetic resonance imaging (MRI) was used for the evaluation before and after NAC. Patients showing either a complete response or partial response in the MRI performed after NAC were classified into the responder group, while patients with either stable disease or progressive disease were categorized into the non-responder group.

For categorical data, Fisher's exact test was used for comparison between the groups. The Mann-Whitney U-test was used to compare continuous variables between the groups. The logistic regression method was used to determine the association between the variables and the response to NAC. A $p$-value $<0.05$ was considered statistically significant. A multivariate analysis was conducted among the significant variables in the univariate analysis, with the calculation of hazard ratios and 95\% confidence intervals. IBM SPSS version 25.0 (SPSS, Chicago, IL, USA) was used for analysis.

\section{Results}

\subsection{Patient and Tumor Characteristics}

We included 246 patients with breast cancer in this study. The median follow-up duration was 28.85 months (interquartile range [IQR], 18.20-41.10 months). The median age was 48 years (IQR, 42-54 years). Thirty-one patients had hypertension (12.6\%), and 17 patients had diabetes mellitus (6.90\%). Among the entire cohort, 71 patients performed regular exercise $(28.9 \%)$. During the treatment, 21 patients showed weight gain $(8.5 \%)$, while 14 patients showed weight loss (5.7\%). Thirty patients had skeletal muscle loss before NAC (12.20\%), while 33 patients were stratified as having skeletal muscle loss based on the post-NAC CT scan (Table 1). Among the 30 patients who showed skeletal muscle loss on the pre-NAC CT scan, 18 showed skeletal muscle loss both on the pre-NAC and post-NAC CT scans (7.3\%), while 12 patients did not show skeletal muscle loss on the post-NAC CT scan (4.9\%). Fifty patients showed a transition to skeletal muscle loss status after NAC (20.3\%). Also, the body mass index (BMI) of the patients was evaluated. Eight 
patients showed underweight, with BMI less than 18.5 (3.3\%), while 43 patients stratified as overweight $(17.5 \%)$.

Table 1. Patient characteristics.

\begin{tabular}{|c|c|c|}
\hline Characteristics & Number & $\%$ \\
\hline Age & \multirow{2}{*}{\multicolumn{2}{|c|}{$48(42-54)$}} \\
\hline Median (IQR) & & \\
\hline \multicolumn{3}{|l|}{ Hypertension } \\
\hline No & 215 & $87.40 \%$ \\
\hline Yes & 31 & $12.60 \%$ \\
\hline \multicolumn{3}{|l|}{ Diabetes mellitus } \\
\hline No & 229 & $93.10 \%$ \\
\hline Yes & 17 & $6.90 \%$ \\
\hline \multicolumn{3}{|l|}{ Exercise } \\
\hline No & 175 & $71.10 \%$ \\
\hline Yes & 71 & $28.90 \%$ \\
\hline \multicolumn{3}{|l|}{ Weight change } \\
\hline No change & 211 & $85.80 \%$ \\
\hline Decrease & 14 & $5.70 \%$ \\
\hline Increase & 21 & $8.50 \%$ \\
\hline \multicolumn{3}{|l|}{ Smoking status } \\
\hline Non-smoker & 241 & $98.00 \%$ \\
\hline Current smoker & 4 & $1.60 \%$ \\
\hline Ex-smoker & 1 & $0.40 \%$ \\
\hline \multicolumn{3}{|l|}{ Drinking status } \\
\hline Non-drinker & 219 & $88.90 \%$ \\
\hline Current drinker & 21 & $8.60 \%$ \\
\hline Ex-drinker & 6 & $2.50 \%$ \\
\hline \multicolumn{3}{|l|}{ Skeletal muscle mass_pre-NAC } \\
\hline Skeletal muscle loss & 30 & $12.20 \%$ \\
\hline Non-skeletal muscle loss & 216 & $87.80 \%$ \\
\hline \multicolumn{3}{|l|}{ Skeletal muscle mass_post-NAC } \\
\hline Skeletal muscle loss & 33 & $13.50 \%$ \\
\hline Non-skeletal muscle loss & 213 & $86.50 \%$ \\
\hline \multicolumn{3}{|l|}{ Change in skeletal muscle mass } \\
\hline Skeletal muscle loss $\rightarrow$ Skeletal muscle loss & 18 & $7.30 \%$ \\
\hline Skeletal muscle loss $\rightarrow$ Non-skeletal muscle loss & 12 & $4.90 \%$ \\
\hline Non-skeletal muscle loss $\rightarrow$ Skeletal muscle loss & 15 & $6.10 \%$ \\
\hline Non-skeletal muscle loss $\rightarrow$ Non-skeletal muscle loss & 201 & $81.70 \%$ \\
\hline \multicolumn{3}{|l|}{ Body mass index } \\
\hline Underweight $(<18.5)$ & 8 & $3.30 \%$ \\
\hline Normal (18.5-23) & 128 & $52.00 \%$ \\
\hline Overweight (23-25) & 43 & $17.50 \%$ \\
\hline Obese $(\geq 25)$ & 67 & $27.20 \%$ \\
\hline \multicolumn{3}{|l|}{ Hemoglobin } \\
\hline Median (IQR) & \multicolumn{2}{|c|}{$13.2(12.5-13.9)$} \\
\hline Platelets & \multirow{2}{*}{\multicolumn{2}{|c|}{$268(229-312)$}} \\
\hline Median (IQR) & & \\
\hline Albumin & \multirow{2}{*}{\multicolumn{2}{|c|}{$4.5(4.3-4.6)$}} \\
\hline Median (IQR) & & \\
\hline Protein & \multirow{2}{*}{\multicolumn{2}{|c|}{$7.4(7.1-7.7)$}} \\
\hline Median (IQR) & & \\
\hline
\end{tabular}


Tumor characteristics are presented in Table 2. The rates of estrogen receptor (ER) and progesterone receptor (PR) positivity were $59.8 \%$ and $30.5 \%$, respectively, and $30.9 \%$ of patients tested positive for human epidermal growth factor receptor 2 (HER2). Sixty-one patients had stage T3/4 tumors (24.8\%), and 114 patients had stage III tumors (46.3\%). Breast-conserving surgery was performed in 129 patients (52.4\%). In terms of adjuvant treatment, 103 patients $(41.9 \%)$ received a selective ER modulator, and 26 patients $(10.6 \%)$ were treated with an aromatase inhibitor. Trastuzumab-based NAC was administered to 72 patients $(29.3 \%)$.

Table 2. Tumor characteristics.

\begin{tabular}{|c|c|c|}
\hline Characteristics & Number & $\%$ \\
\hline \multicolumn{3}{|l|}{ Pathology } \\
\hline IDC & 232 & $94.30 \%$ \\
\hline ILC & 5 & $2.05 \%$ \\
\hline Mucinous & 5 & $2.05 \%$ \\
\hline Others & 4 & $1.60 \%$ \\
\hline \multicolumn{3}{|l|}{ Clinical T stage } \\
\hline $\mathrm{T} 1$ & 46 & $18.70 \%$ \\
\hline T2 & 139 & $56.50 \%$ \\
\hline T3 & 34 & $13.80 \%$ \\
\hline $\mathrm{T} 4$ & 27 & $11.00 \%$ \\
\hline \multicolumn{3}{|l|}{ Clinical N stage } \\
\hline No & 58 & $23.60 \%$ \\
\hline N1 & 98 & $39.80 \%$ \\
\hline N2 & 49 & $19.90 \%$ \\
\hline N3 & 41 & $16.70 \%$ \\
\hline \multicolumn{3}{|l|}{ Stage } \\
\hline I & 9 & $3.70 \%$ \\
\hline II & 123 & $50.00 \%$ \\
\hline III & 114 & $46.30 \%$ \\
\hline \multicolumn{3}{|l|}{ Operation } \\
\hline Breast-conserving surgery & 129 & $52.40 \%$ \\
\hline Modified radical mastectomy & 117 & $47.60 \%$ \\
\hline \multicolumn{3}{|l|}{ RT modality } \\
\hline 3D CRT & 57 & $23.20 \%$ \\
\hline IMRT & 189 & $76.80 \%$ \\
\hline \multicolumn{3}{|l|}{ Dose scheme } \\
\hline 180 cGy per fraction & 226 & $91.90 \%$ \\
\hline 200 cGy per fraction & 8 & $3.20 \%$ \\
\hline 267 cGy per fraction & 12 & $4.90 \%$ \\
\hline \multicolumn{3}{|l|}{ ER } \\
\hline Negative & 99 & $40.20 \%$ \\
\hline Positive & 147 & $59.80 \%$ \\
\hline \multicolumn{3}{|l|}{ PR } \\
\hline Negative & 171 & $69.50 \%$ \\
\hline Positive & 75 & $30.50 \%$ \\
\hline \multicolumn{3}{|l|}{ HER2 } \\
\hline Negative & 170 & $69.10 \%$ \\
\hline Positive & 76 & $30.90 \%$ \\
\hline \multicolumn{3}{|l|}{ Ki-67 } \\
\hline$<15$ & 112 & $45.50 \%$ \\
\hline$\geq 15$ & 78 & $31.70 \%$ \\
\hline Unknown & 56 & $22.80 \%$ \\
\hline
\end{tabular}


Table 2. Cont.

\begin{tabular}{|c|c|c|}
\hline Characteristics & Number & $\%$ \\
\hline \multicolumn{3}{|l|}{ Chemotherapy regimen } \\
\hline Adriamycin based & 5 & $2.00 \%$ \\
\hline Adriamycin and taxol based & 161 & $65.40 \%$ \\
\hline Taxol based & 8 & $3.30 \%$ \\
\hline Trastuzumab based & 72 & $29.30 \%$ \\
\hline \multicolumn{3}{|c|}{ Selective estrogen receptor modulator } \\
\hline No & 143 & $58.10 \%$ \\
\hline Yes & 103 & $41.90 \%$ \\
\hline \multicolumn{3}{|l|}{ Aromatase inhibitor } \\
\hline No & 220 & $89.40 \%$ \\
\hline Yes & 26 & $10.60 \%$ \\
\hline
\end{tabular}

\subsection{Cut-Off Value of the SMI for Skeletal Muscle Loss Group}

We used the receiver operating characteristic (ROC) curve to determine the optimal cut-off value of SMI at the T4 level as there is no established value. The SMI value of 6, both pre-NAC and post-NAC, showed good sensitivity and specificity for responsiveness to NAC. On the basis of the area under the ROC curve (AUC) of 0.732 (Figure 2), we identified the pre-NAC SMI at the T4 level as a good predictor of responsiveness to NAC. Figure 3 demonstrates the ROC curve of the post-NAC SMI for predicting responsiveness to NAC; the AUC was 0.885 , indicating that it was as an excellent predictor.

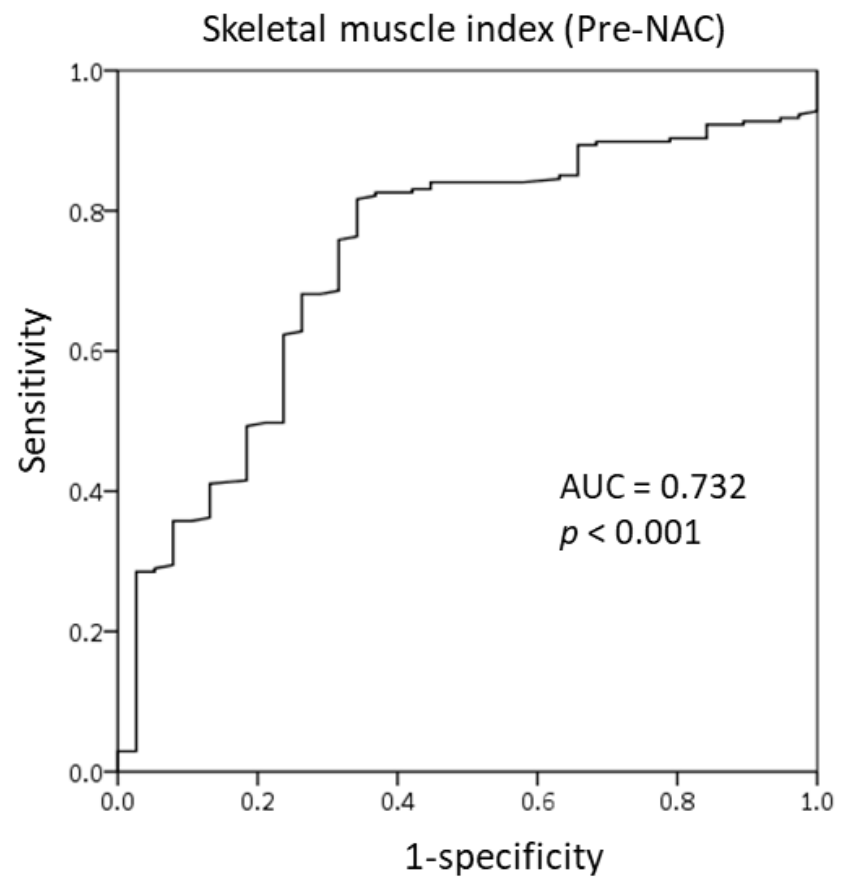

Figure 2. Receiver operating characteristic curve of the skeletal muscle index at the T4 level prior to the initiation of neoadjuvant chemotherapy. 


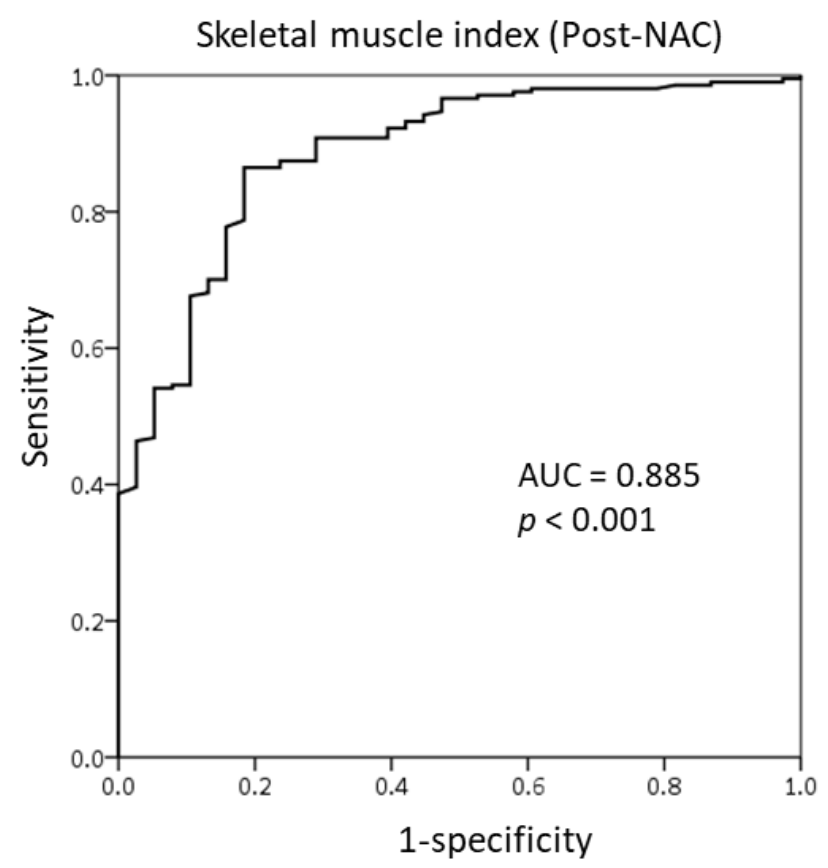

Figure 3. Receiver operating characteristic curve of the skeletal muscle index at the T4 level after the completion of neoadjuvant chemotherapy.

\subsection{Predictive Value of Subcutaneous Adipose Tissue Index}

We also analyzed the subcutaneous adipose tissue index (SATI) to evaluate whether the SATI can predict the response to NAC. Both the pre-NAC and post-NAC SATI showed poor specificity and sensitivity in predicting responsiveness to NAC (Figures S1 and S2). The AUCs of pre-NAC and post-NAC SATI were 0.560 and 0.587 , respectively, indicating SATI to be a poor predictive tool.

\subsection{Comparison of Patient and Tumor Characteristics Between the Responder and Non-Responder Groups}

Among the 246 patients, 208 patients responded well to NAC, while 38 patients showed a poor response. Most of the variables were well balanced between the responder and non-responder groups. Skeletal muscle loss at both the pre-NAC and post-NAC were associated with responsiveness to NAC. The non-responder group included more patients with skeletal muscle loss (non-responder group vs. responder group: pre-NAC skeletal muscle loss patients; $23.7 \%$ vs. $10.1 \%, p=0.019$, post-NAC skeletal muscle loss patients; $55.3 \%$ vs. $5.8 \%, p<0.001$ ) (Table 3 ). The non-responder group had more features of tumor aggressiveness, such as advanced stage and a high Ki-67 index (responder group vs. nonresponder group: stage III, $41.8 \%$ vs. $71.10 \%, p=0.003$; Ki- 67 index $\geq 15 \%, 28.8 \%$ vs. $47.4 \%$, $p=0.001)$ (Table 4). 
Table 3. Comparison of patient characteristics according to the response to NAC.

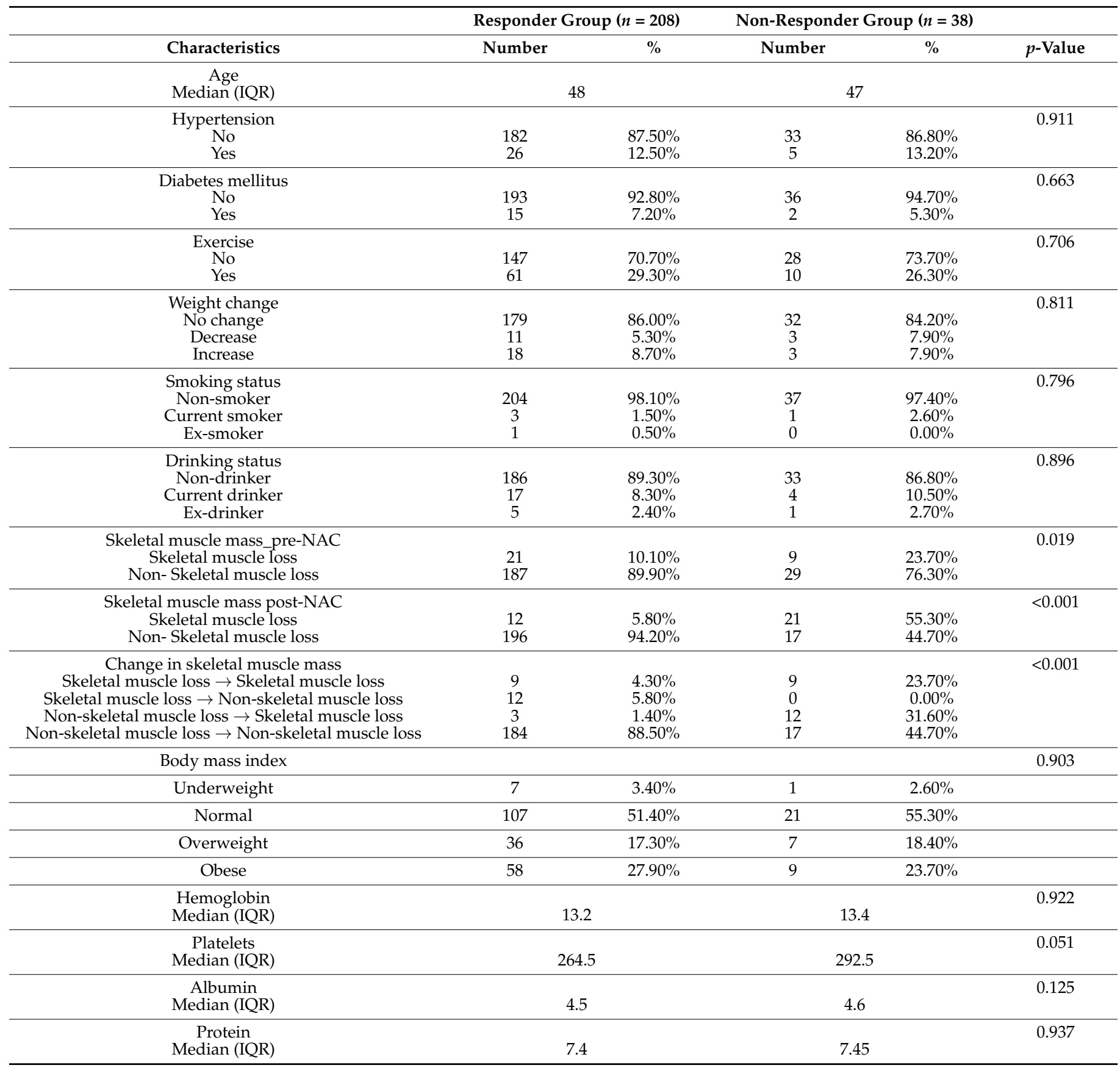

Abbreviations: IQR, Interquartile range; NAC, Neoadjuvant chemotherapy.

Table 4. Comparison of tumor characteristics according to the response to neoadjuvant chemotherapy.

\begin{tabular}{|c|c|c|c|c|c|}
\hline \multirow[b]{2}{*}{ Characteristics } & \multicolumn{2}{|c|}{ Responder Group $(n=208)$} & \multicolumn{2}{|c|}{ Non-Responder Group $(n=38)$} & \multirow[b]{2}{*}{$p$-Value } \\
\hline & Number & $\%$ & Number & $\%$ & \\
\hline $\begin{array}{c}\text { Pathology } \\
\text { IDC } \\
\text { ILC } \\
\text { Mucinous } \\
\text { Others }\end{array}$ & $\begin{array}{c}201 \\
2 \\
2 \\
3\end{array}$ & $\begin{array}{c}96.60 \% \\
1.00 \% \\
1.00 \% \\
1.40 \%\end{array}$ & $\begin{array}{c}31 \\
3 \\
3 \\
1\end{array}$ & $\begin{array}{c}81.60 \% \\
7.90 \% \\
7.90 \% \\
2.60 \%\end{array}$ & 0.001 \\
\hline $\begin{array}{l}\text { T stage } \\
\text { T1 } \\
\text { T2 } \\
\text { T3 } \\
\text { T4 }\end{array}$ & $\begin{array}{c}42 \\
120 \\
26 \\
20\end{array}$ & $\begin{array}{c}20.20 \% \\
57.70 \% \\
12.50 \% \\
9.60 \%\end{array}$ & $\begin{array}{c}4 \\
19 \\
8 \\
7\end{array}$ & $\begin{array}{l}10.50 \% \\
50.00 \% \\
21.10 \% \\
18.40 \%\end{array}$ & 0.116 \\
\hline
\end{tabular}


Table 4. Cont.

\begin{tabular}{|c|c|c|c|c|c|}
\hline \multirow[b]{2}{*}{ Characteristics } & \multicolumn{2}{|c|}{ Responder Group $(n=208)$} & \multicolumn{2}{|c|}{ Non-Responder Group $(n=38)$} & \multirow[b]{2}{*}{$p$-Value } \\
\hline & Number & $\%$ & Number & $\%$ & \\
\hline N stage & & & & & 0.076 \\
\hline No & 52 & $25.00 \%$ & 6 & $15.80 \%$ & \\
\hline N1 & 87 & $41.80 \%$ & 11 & $28.90 \%$ & \\
\hline N2 & 37 & $17.80 \%$ & 12 & $31.60 \%$ & \\
\hline N3 & 32 & $15.40 \%$ & 9 & $23.70 \%$ & \\
\hline Stage & & & & & 0.003 \\
\hline I & 9 & $4.30 \%$ & 0 & $0.00 \%$ & \\
\hline II & 112 & $53.90 \%$ & 11 & $28.90 \%$ & \\
\hline III & 87 & $41.80 \%$ & 27 & $71.10 \%$ & \\
\hline Operation & & & & & $<0.001$ \\
\hline Breast-conserving surgery & 120 & $57.70 \%$ & 9 & $23.70 \%$ & \\
\hline Modified radical mastectomy & 88 & $42.30 \%$ & 29 & $76.30 \%$ & \\
\hline RT modality & & & & & 0.241 \\
\hline 3D CRT & 51 & $24.50 \%$ & 6 & $15.80 \%$ & \\
\hline IMRT & 157 & $75.50 \%$ & 32 & $84.20 \%$ & \\
\hline Dose scheme & & & & & 0.354 \\
\hline 180 cGy per fraction & 189 & $90.90 \%$ & 37 & $97.40 \%$ & \\
\hline 200 cGy per fraction & 8 & $3.80 \%$ & 0 & $0.00 \%$ & \\
\hline 267 cGy per fraction & 11 & $5.30 \%$ & 1 & $2.60 \%$ & \\
\hline ER & & & & & 0.236 \\
\hline Negative & 87 & $41.80 \%$ & 12 & $31.60 \%$ & \\
\hline Positive & 121 & $58.20 \%$ & 26 & $68.40 \%$ & \\
\hline PR & & & & & 0.874 \\
\hline Negative & 145 & $69.70 \%$ & 26 & $68.40 \%$ & \\
\hline Positive & 63 & $30.30 \%$ & 12 & $31.60 \%$ & \\
\hline HER2 & & & & & 0.296 \\
\hline Negative & 141 & $67.80 \%$ & 29 & $76.30 \%$ & \\
\hline Positive & 67 & $32.20 \%$ & 9 & $23.70 \%$ & \\
\hline Ki-67 & & & & & 0.001 \\
\hline$<15$ & 92 & $44.20 \%$ & 20 & $52.60 \%$ & \\
\hline$\geq 15$ & 60 & $28.80 \%$ & 18 & $47.40 \%$ & \\
\hline Unknown & 56 & $27.00 \%$ & 0 & $0.00 \%$ & \\
\hline Chemotherapy regimen & & & & & $<0.001$ \\
\hline Adriamycin based & 1 & $0.50 \%$ & 4 & $10.50 \%$ & \\
\hline Adriamycin and taxol based & 138 & $66.30 \%$ & 23 & $60.50 \%$ & \\
\hline Taxol based & 5 & $2.40 \%$ & 3 & $7.90 \%$ & \\
\hline Trastuzumab based & 64 & $30.80 \%$ & 8 & $21.10 \%$ & \\
\hline Selective estrogen receptor modulator & & & & & 0.162 \\
\hline No & 117 & $56.25 \%$ & 26 & $68.40 \%$ & \\
\hline Yes & 91 & $43.75 \%$ & 12 & $31.60 \%$ & \\
\hline Aromatase inhibitor & & & & & 0.560 \\
\hline No & 185 & $88.90 \%$ & 35 & $92.10 \%$ & \\
\hline Yes & 23 & $11.10 \%$ & 3 & $7.90 \%$ & \\
\hline
\end{tabular}

Abbreviations: IDC, Invasive ductal carcinoma; ILC, Invasive lobular carcinoma; T stage, Tumor stage; N stage, Node stage; RT, Radiotherapy; 3D CRT, 3-dimensional conformal radiotherapy; IMRT, Intensity-modulated radiation therapy; ER, Estrogen receptor; PR, Progesterone receptor, HER2, Human epidermal growth factor receptor 2.

\subsection{Univariate and Multivariate Analyses of the Response to Neoadjuvant Chemotherapy}

In the multivariate Cox proportional hazard models, post-NAC skeletal muscle loss was significantly associated with the response to NAC (Table 5). Pre-NAC skeletal muscle loss could also significantly predict the response to NAC. Along with skeletal muscle loss, advanced disease stage was associated with a significantly poorer response to NAC (hazard ratio $0.28,95 \%$ confidence interval $0.11-0.71, p=0.007$ ). 
Table 5. Univariate and multivariate analyses of the response to NAC.

\begin{tabular}{|c|c|c|c|c|c|c|}
\hline \multirow[b]{2}{*}{ Variables } & \multicolumn{3}{|c|}{ Univariate Analysis } & \multicolumn{3}{|c|}{ Multivariate Analysis } \\
\hline & HR & $95 \% \mathrm{CI}$ & $p$-Value & HR & $95 \% \mathrm{CI}$ & $p$-Value \\
\hline Age (<48 vs. $\geq 48$ years) & 1.322 & $0.66-2.64$ & 0.430 & & & \\
\hline Smoking status & & & 0.877 & & & \\
\hline Non-smoker vs. current smoker & 0.550 & $0.06-5.43$ & 0.608 & & & \\
\hline Non-smoker vs. ex-smoker & NA & NA & NA & & & \\
\hline Drinking status & & & 0.896 & & & \\
\hline Non-drinker vs. current drinker & 0.762 & $0.24-2.41$ & 0.644 & & & \\
\hline Non-drinker vs. ex-drinker & 0.897 & $0.10-7.92$ & 0.922 & & & \\
\hline $\begin{array}{l}\text { Pre-NAC skeletal muscle mass (Skeletal } \\
\text { muscle loss vs. non-skeletal muscle loss) }\end{array}$ & 2.749 & $1.15-6.58$ & 0.023 & 0.193 & $0.04-0.94$ & 0.042 \\
\hline $\begin{array}{l}\text { Post-NAC skeletal muscle mass (Skeletal } \\
\text { muscle loss vs. non-skeletal muscle loss) }\end{array}$ & 20.074 & $8.45-47.69$ & $<0.001$ & 64.566 & $15.13-275.58$ & $<0.001$ \\
\hline Change in skeletal muscle mass $^{+}$ & & & $<0.001$ & & & \\
\hline Group 1 vs. 2 & $\mathrm{~N} / \mathrm{A}$ & $\mathrm{N} / \mathrm{A}$ & 0.999 & & & \\
\hline Group 1 vs. 3 & 0.250 & $0.52-1.20$ & 0.083 & & & \\
\hline Group 1 vs. 4 & 10.824 & $3.79-30.90$ & $<0.001$ & & & \\
\hline Body mass index & & & 0.904 & & & \\
\hline Underweight vs. Obese & 1.086 & $0.12-9.90$ & 0.942 & & & \\
\hline Normal vs. Obese & 0.739 & $0.32-1.72$ & 0.483 & & & \\
\hline Overweight vs. Obese & 0.798 & $0.27-2.33$ & 0.680 & & & \\
\hline ER (negative vs. positive) & 0.723 & $0.35-1.49$ & 0.381 & & & \\
\hline PR (negative vs. positive) & 1.028 & $0.51-2.07$ & 0.938 & & & \\
\hline HER2 (negative vs. positive) & 1.465 & $0.66-3.27$ & 0.352 & & & \\
\hline Ki-67 (<15 vs. $\geq 15)$ & 0.725 & $0.35-1.48$ & 0.377 & & & \\
\hline Pathology & & & 0.009 & & & 0.056 \\
\hline IDC vs. ILC & 0.103 & $0.02-0.64$ & 0.015 & 1.209 & $0.09-16.90$ & 0.888 \\
\hline IDC vs. mucinous & 0.103 & $0.02-0.64$ & 0.015 & 0.067 & $0.01-0.47$ & 0.006 \\
\hline IDC vs. others & 0.463 & $0.05-4.59$ & 0.510 & 0.640 & $0.03-12.71$ & 0.770 \\
\hline T stage & & & 0.131 & & & \\
\hline T1 vs. T2 & 0.602 & $0.19-1.87$ & 0.380 & & & \\
\hline T1 vs. T3 & 0.310 & $0.09-1.13$ & 0.076 & & & \\
\hline T1 vs. T4 & 0.272 & $0.07-1.04$ & 0.057 & & & \\
\hline N stage & & & 0.086 & & & \\
\hline N0 vs. N1 & 0.913 & $0.32-2.61$ & 0.865 & & & \\
\hline N0 vs. N2 & 0.356 & $0.12-1.03$ & 0.058 & & & \\
\hline N0 vs. N3 & 0.410 & $0.13-1.26$ & 0.120 & & & \\
\hline Stage (stage I/II vs. stage III) & 0.293 & $0.14-0.62$ & 0.001 & 0.276 & $0.11-0.71$ & 0.007 \\
\hline
\end{tabular}

Abbreviations: NAC, Neoadjuvant chemotherapy; HR, Hazard ratio; CI, Confidence interval; NA, Not applicable; ER, Estrogen receptor; PR, Progesterone receptor, HER2, Human epidermal growth factor receptor 2; IDC, Invasive ductal carcinoma; ILC, Invasive lobular carcinoma; T stage, Tumor stage; N stage, Node stage. ${ }^{\dagger}$ Group 1: Patients with skeletal muscle loss in both pre-NAC and post-NAC, Group 2: Patients who had skeletal muscle loss in pre-NAC but changed to non-skeletal muscle loss in post-NAC, Group 3: Patients who changed from non-skeletal muscle loss in pre-NAC to skeletal muscle loss in post-NAC, Group 4: Patients with non-skeletal muscle loss in both pre-NAC and post-NAC.

\section{Discussion}

To our knowledge, this is the first study to evaluate the association between skeletal muscle loss and the response to NAC in patients with locally advanced breast cancer. Post-NAC skeletal muscle loss is more strongly related to responsiveness to NAC than pre-NAC skeletal muscle loss. We also classified the adiposity value to evaluate its effect on the response to NAC, but there was no association. 
CT-determined skeletal muscle mass is usually evaluated at the level of the L3 spine. We used the SMI at the T4 level for easy evaluation as all patients with breast cancer underwent chest CT before the start and after the completion of NAC. There is no defined cut-off value for the SMI at the T4 level to evaluate skeletal muscle mass. For this reason, the value determined by the ROC curve was set as the cut-off value in this study. Further studies are needed to establish the optimal cut-off value of the SMI at the T4 level for skeletal muscle loss.

In our study, skeletal muscle loss was significantly associated with the response to NAC. There are several approaches to predicting the response to NAC. Physicians have been trying to predict the effect of NAC using imaging tools [11,12] and biomarkers [13,14]. However, the obvious significant factors related to the response to NAC have not yet been defined. This may be due to the diverse clinical outcomes depending on the molecular subtypes of breast cancer [15]. We demonstrated that skeletal muscle loss is one of the predictive markers for the response to NAC. Along with skeletal muscle loss, the clinical stage of the cancer can predict the response to NAC. This is concordant with previous studies showing that the clinical stage is associated with the response to NAC [16-18]. More advanced stage or a larger tumor size are related to a poorer response to NAC, indicating that a higher tumor burden may have a negative impact on the response to treatment.

Obesity is regarded as a poor prognostic factor for breast cancer [19,20]. Patients with a high body mass index (BMI) have been reported to achieve fewer pathologic complete responses after NAC [21,22]. This would indicate the significance of BMI as a predictive factor for the response to NAC. However, there was no relation between high adiposity and the response to NAC in this study. There can be two reasons for this. First, the assessment of obesity differed according to studies. We assessed obesity based on CT-determined SATI, while other studies evaluated obesity using BMI. The results could vary because of differences in measurement methods. Another possible reason is the racial difference. The number of people with a high BMI is lower in Asian populations than in Caucasian populations, and the proportion of patients with obesity was much lower in Asians [23]. Our study could be inadequate to demonstrate an association between obesity and the response to NAC as the number of patients with obesity was inadequate.

Recent studies have demonstrated that a low level of muscle mass is highly associated with inflammation markers [24,25]. The local immune response drives muscle breakdown and, consequently, leads to systemic inflammation and tumor growth [26]. Indicators of inflammation were well-correlated with the response to treatment in various malignancies $[27,28]$. One study reported that inflammation is a key factor for chemotherapy-induced skeletal muscle loss in patients with cancer [29]. The levels of inflammatory cytokines, such as interleukin 8, tumor necrosis factor alpha, and C-reactive protein, were increased in patients with treatment-induced skeletal muscle loss, while no changes occurred in patients without treatment-induced skeletal muscle loss. Thus, inflammation might play a key role in enhancing treatment-induced skeletal muscle loss and affecting the response to NAC. Several studies reported that skeletal muscle loss is associated with chemotherapy toxicity $[30,31]$. Besides, one study reported that skeletal muscle loss is associated with intolerance to treatment [32]. Prospective clinical trials are needed to further understand the relation between the loss of muscle mass, inflammation, and the response to NAC as well as the mechanisms underlying these relationships.

There are several limitations to this study. Due to the retrospective nature, the causal relationships between the variables and skeletal muscle loss could not be determined. The results of this study indicated that muscle wasting at the end of neoadjuvant treatment is more associated with the response to treatment. Muscle wasting during treatment could be influenced by tumor aggressiveness. Due to this reason, careful attention should be paid in interpreting the results. Furthermore, data for some of the variables were unavailable. For example, we could not evaluate inflammatory status based on the levels of C-reactive protein, an objective marker for inflammatory status. Further, due to the short follow-up, we could not evaluate survival parameters such as overall survival and progression-free 
survival. Lastly, the cut-off value of the SMI was not a confirmed optimal cut-off value. Further studies are needed to determine the optimal cut-off value for CT-determined skeletal muscle loss. Despite these limitations, this is the first study demonstrating the relationship between chemotherapy-induced skeletal muscle loss and the response to NAC.

\section{Conclusions}

We observed that skeletal muscle loss, especially treatment-induced skeletal muscle loss, is associated with the response to NAC in patients with locally advanced breast cancer. The cancer stage is also significantly associated with a poor response to NAC. In the era of precision medicine, an accurate measurement of muscle mass will help guide treatment to achieve optimal clinical outcomes. Muscle-strengthening exercises, nutritional support, and pharmacologic intervention would be helpful in delaying muscle degradation and consequently enhancing the response to NAC in patients with breast cancer.

Supplementary Materials: The following are available online at https:/ /www.mdpi.com/article/10 .3390/cancers13081806/s1, Figure S1: Receiver operating characteristic curve of the subcutaneous adipose tissue index at the T4 spine prior to the initiation of neoadjuvant chemotherapy, Figure S2: Receiver operating characteristic curve of $\mathrm{T} 4$ spine subcutaneous adipose tissue index after completion of neoadjuvant chemotherapy.

Author Contributions: Conceptualization, B.M.L. and I.J.L.; methodology, Y.C. and S.G.A.; formal analysis, B.M.L. and J.W.K.; resources, H.C.J.; data curation, J.H.K. and H.C.J.; writing-original draft preparation, B.M.L.; writing—review and editing, I.J.L. and J.J.; supervision, H.C.J.; funding acquisition, I.J.L. All authors have read and agreed to the published version of the manuscript.

Funding: This research was supported by a project grant funded by the Ministry of Health \& Welfare, Republic of Korea (grant number: HI19C1330) and a National Research Foundation of Korea Grant funded by the Korean Government (No. NRF-2019R1A2C1085958).

Institutional Review Board Statement: This study was conducted according to the guidelines of the Declaration of Helsinki, and approved by the institutional review board of the Gangnam Severance Hospital (protocol code 3-2020-0509 and date of approval: 8 February 2021).

Informed Consent Statement: Patient consent was waived as the study was a retrospective study.

Data Availability Statement: The data presented in this study are available on request from the corresponding author. The data are not publicly available due to privacy.

Acknowledgments: The abstract of this study was presented in poster presentation at the 46th Annual Meeting of Korean Cancer Association on 12-13 November 2020.

Conflicts of Interest: The authors declare no conflict of interest.

\section{References}

1. Schwartz, G.F.; Birchansky, C.A.; Komarnicky, L.T.; Mansfield, C.M.; Cantor, R.I.; Biermann, W.A.; Fellin, F.M.; McFarlane, J. Induction chemotherapy followed by breast conservation for locally advanced carcinoma of the breast. Cancer 1994, 73, 362-369. [CrossRef]

2. Hortobagyi, G.N.; Ames, F.C.; Buzdar, A.U.; Kau, S.W.; McNeese, M.D.; Paulus, D.; Hug, V.; Holmes, F.A.; Romsdahl, M.M.; Fraschini, G.; et al. Management of stage iii primary breast cancer with primary chemotherapy, surgery, and radiation therapy. Cancer 1988, 62, 2507-2516. [CrossRef]

3. Fisher, B.; Brown, A.; Mamounas, E.; Wieand, S.; Robidoux, A.; Margolese, R.G.; Cruz, A.B., Jr.; Fisher, E.R.; Wickerham, D.L.; Wolmark, N.; et al. Effect of preoperative chemotherapy on local-regional disease in women with operable breast cancer: Findings from national surgical adjuvant breast and bowel project b-18. J. Clin. Oncol. 1997, 15, 2483-2493. [CrossRef]

4. Semiglazov, V.; Eiermann, W.; Zambetti, M.; Manikhas, A.; Bozhok, A.; Lluch, A.; Tjulandin, S.; Sabadell, M.D.; Caballero, A.; Valagussa, P.; et al. Surgery following neoadjuvant therapy in patients with her2-positive locally advanced or inflammatory breast cancer participating in the neoadjuvant herceptin (noah) study. Eur. J. Surg. Oncol. 2011, 37, 856-863. [CrossRef]

5. Antoun, S.; Baracos, V.E.; Birdsell, L.; Escudier, B.; Sawyer, M.B. Low body mass index and sarcopenia associated with doselimiting toxicity of sorafenib in patients with renal cell carcinoma. Ann. Oncol. 2010, 21, 1594-1598. [CrossRef]

6. Prado, C.M.M.; Baracos, V.E.; McCargar, L.J.; Reiman, T.; Mourtzakis, M.; Tonkin, K.; Mackey, J.R.; Koski, S.; Pituskin, E.; Sawyer, M.B. Sarcopenia as a determinant of chemotherapy toxicity and time to tumor progression in metastatic breast cancer patients receiving capecitabine treatment. Clin. Cancer Res. 2009, 15, 2920-2926. [CrossRef] 
7. Kazemi-Bajestani, S.M.; Mazurak, V.C.; Baracos, V. Computed tomography-defined muscle and fat wasting are associated with cancer clinical outcomes. Semin. Cell Dev. Biol. 2016, 54, 2-10. [CrossRef] [PubMed]

8. Van der Kroft, G.; van Dijk, D.P.J.; Rensen, S.S.; van Tiel, F.H.; de Greef, B.; West, M.; Ostridge, K.; Dejong, C.H.C.; Neumann, U.P.; Damink, S.W.M.O. Low thoracic muscle radiation attenuation is associated with postoperative pneumonia following partial hepatectomy for colorectal metastasis. HPB Oxf. 2020, 22, 1011-1019. [CrossRef] [PubMed]

9. Dabiri, S.; Popuri, K.; Feliciano, E.M.C.; Caan, B.J.; Baracos, V.E.; Beg, M.F. Muscle segmentation in axial computed tomography (ct) images at the lumbar (13) and thoracic (t4) levels for body composition analysis. Comput. Med. Imaging Graph. 2019, 75, 47-55. [CrossRef] [PubMed]

10. Eisenhauer, E.A.; Therasse, P.; Bogaerts, J.; Schwartz, L.H.; Sargent, D.; Ford, R.; Dancey, J.; Arbuck, S.; Gwyther, S.; Mooney, M.; et al. New response evaluation criteria in solid tumours: Revised recist guideline (version 1.1). Eur. J. Cancer 2009, 45, 228-247. [CrossRef]

11. Kim, H.; Kim, H.H.; Park, J.S.; Shin, H.J.; Cha, J.H.; Chae, E.Y.; Choi, W.J. Prediction of pathological complete response of breast cancer patients undergoing neoadjuvant chemotherapy: Usefulness of breast mri computer-aided detection. Br. J. Radiol. 2014, 87, 20140142. [CrossRef]

12. Choi, J.H.; Lim, H.I.; Lee, S.K.; Kim, W.W.; Kim, S.M.; Cho, E.; Ko, E.Y.; Han, B.K.; Park, Y.H.; Ahn, J.S.; et al. The role of pet ct to evaluate the response to neoadjuvant chemotherapy in advanced breast cancer: Comparison with ultrasonography and magnetic resonance imaging. J. Surg. Oncol. 2010, 102, 392-397. [CrossRef] [PubMed]

13. Lin, X.; Xu, R.; Mao, S.; Zhang, Y.; Dai, Y.; Guo, Q.; Song, X.; Zhang, Q.; Li, L.; Chen, Q. Metabolic biomarker signature for predicting the effect of neoadjuvant chemotherapy of breast cancer. Ann. Transl. Med. 2019, 7, 670. [CrossRef] [PubMed]

14. Zhang, F.; Huang, M.; Zhou, H.; Chen, K.; Jin, J.; Wu, Y.; Ying, L.; Ding, X.; Su, D.; Zou, D. A nomogram to predict the pathologic complete response of neoadjuvant chemotherapy in triple-negative breast cancer based on simple laboratory indicators. Ann. Surg. Oncol. 2019, 26, 3912-3919. [CrossRef] [PubMed]

15. Desmedt, C.; Haibe-Kains, B.; Wirapati, P.; Buyse, M.; Larsimont, D.; Bontempi, G.; Delorenzi, M.; Piccart, M.; Sotiriou, C. Biological processes associated with breast cancer clinical outcome depend on the molecular subtypes. Clin. Cancer Res. 2008, 14, 5158-5165. [CrossRef] [PubMed]

16. Goorts, B.; van Nijnatten, T.J.A.; de Munck, L.; Moossdorff, M.; Heuts, E.M.; de Boer, M.; Lobbes, M.B.I.; Smidt, M.L. Clinical tumor stage is the most important predictor of pathological complete response rate after neoadjuvant chemotherapy in breast cancer patients. Breast Cancer Res. Treat. 2017, 163, 83-91. [CrossRef] [PubMed]

17. Bonadonna, G.; Veronesi, U.; Brambilla, C.; Ferrari, L.; Luini, A.; Greco, M.; Bartoli, C.; de Yoldi, G.C.; Zucali, R.; Rilke, F.; et al. Primary chemotherapy to avoid mastectomy in tumors with diameters of three centimeters or more. J. Natl. Cancer Inst. 1990, 82, 1539-1545. [CrossRef] [PubMed]

18. Gajdos, C.; Tartter, P.I.; Estabrook, A.; Gistrak, M.A.; Jaffer, S.; Bleiweiss, I.J. Relationship of clinical and pathologic response to neoadjuvant chemotherapy and outcome of locally advanced breast cancer. J. Surg. Oncol. 2002, 80, 4-11. [CrossRef]

19. Loi, S.; Milne, R.L.; Friedlander, M.L.; McCredie, M.R.; Giles, G.G.; Hopper, J.L.; Phillips, K.A. Obesity and outcomes in premenopausal and postmenopausal breast cancer. Cancer Epidemiol. Biomarkers Prev. 2005, 14, 1686-1691. [CrossRef]

20. Kroenke, C.H.; Chen, W.Y.; Rosner, B.; Holmes, M.D. Weight, weight gain, and survival after breast cancer diagnosis. J. Clin. Oncol. 2005, 23, 1370-1378. [CrossRef]

21. Del Fabbro, E.; Parsons, H.; Warneke, C.L.; Pulivarthi, K.; Litton, J.K.; Dev, R.; Palla, S.L.; Brewster, A.; Bruera, E. The relationship between body composition and response to neoadjuvant chemotherapy in women with operable breast cancer. Oncologist 2012, 17, 1240-1245. [CrossRef]

22. Litton, J.K.; Gonzalez-Angulo, A.M.; Warneke, C.L.; Buzdar, A.U.; Kau, S.W.; Bondy, M.; Mahabir, S.; Hortobagyi, G.N.; Brewster, A.M. Relationship between obesity and pathologic response to neoadjuvant chemotherapy among women with operable breast cancer. J. Clin. Oncol. 2008, 26, 4072-4077. [CrossRef]

23. Wulan, S.N.; Westerterp, K.R.; Plasqui, G. Ethnic differences in body composition and the associated metabolic profile: A comparative study between asians and caucasians. Maturitas 2010, 65, 315-319. [CrossRef] [PubMed]

24. Malietzis, G.; Lee, G.H.; Bernardo, D.; Blakemore, A.I.; Knight, S.C.; Moorghen, M.; Al-Hassi, H.O.; Jenkins, J.T. The prognostic significance and relationship with body composition of ccr7-positive cells in colorectal cancer. J. Surg. Oncol. 2015, 112, 86-92. [CrossRef] [PubMed]

25. Feliciano, E.M.C.; Kroenke, C.H.; Meyerhardt, J.A.; Prado, C.M.; Bradshaw, P.T.; Kwan, M.L.; Xiao, J.; Alexeeff, S.; Corley, D.; Weltzien, E.; et al. Association of systemic inflammation and sarcopenia with survival in nonmetastatic colorectal cancer: Results from the c scans study. JAMA Oncol. 2017, 3, e172319. [CrossRef]

26. Hubbard, J.M.; Cohen, H.J.; Muss, H.B. Incorporating biomarkers into cancer and aging research. J. Clin. Oncol. 2014, 32, 2611-2616. [CrossRef] [PubMed]

27. Kim, T.G.; Park, W.; Kim, H.; Choi, D.H.; Park, H.C.; Kim, S.H.; Cho, Y.B.; Yun, S.H.; Kim, H.C.; Lee, W.Y.; et al. Baseline neutrophil-lymphocyte ratio and platelet-lymphocyte ratio in rectal cancer patients following neoadjuvant chemoradiotherapy. Tumori J. 2019, 105, 434-440. [CrossRef] [PubMed]

28. Takeda, T.; Takeuchi, M.; Saitoh, M.; Takeda, S. Neutrophil-to-lymphocyte ratio after four weeks of nivolumab administration as a predictive marker in patients with pretreated non-small-cell lung cancer. Thorac. Cancer 2018, 9, 1291-1299. [CrossRef] [PubMed] 
29. Oflazoglu, U.; Alacacioglu, A.; Varol, U.; Kucukzeybek, Y.; Salman, T.; Onal, H.T.; Yilmaz, H.E.; Yildiz, Y.; Taskaynatan, H.; Saray, S.; et al. The role of inflammation in adjuvant chemotherapy-induced sarcopenia (izmir oncology group (izog) study). Support. Care Cancer 2020, 28, 3965-3977. [CrossRef]

30. Chemama, S.; Bayar, M.A.; Lanoy, E.; Ammari, S.; Stoclin, A.; Goere, D.; Elias, D.; Raynard, B.; Antoun, S. Sarcopenia is associated with chemotherapy toxicity in patients undergoing cytoreductive surgery with hyperthermic intraperitoneal chemotherapy for peritoneal carcinomatosis from colorectal cancer. Ann. Surg. Oncol. 2016, 23, 3891-3898. [CrossRef]

31. Tan, B.; Brammer, K.; Randhawa, N.; Welch, N.; Parsons, S.; James, E.; Catton, J. Sarcopenia is associated with toxicity in patients undergoing neo-adjuvant chemotherapy for oesophago-gastric cancer. Brit. J. Surg. 2014, 101, 40. [CrossRef] [PubMed]

32. Cho, Y.; Kim, J.W.; Keum, K.C.; Lee, C.G.; Jeung, H.C.; Lee, I.J. Prognostic significance of sarcopenia with inflammation in patients with head and neck cancer who underwent definitive chemoradiotherapy. Front. Oncol. 2018, 8, 457. [CrossRef] [PubMed] 